\title{
EFFECTS OF DIFFERENT EXPOSURE TIMES OF LED LIGHTS ON POSTHARVEST PERFORMANCES OF FRESH-CUT PINEAPPLE (Ananas comosus L. cv. Josapine)
}

\author{
LEONG JIA QI AND WAN ZALIHA WAN SEMBOK* \\ School of Food Science and Technology, Universiti Malaysia Terengganu, 21030 Kuala Nerus, Terengganu, \\ Malaysia
}

*Corresponding author:wzaliha@umt.edu.my

\begin{abstract}
Pineapple is one of the most important commercial fruit crops served in freshcut form which is convenient for the consumers. However, fresh-cut pineapple induces the activity of phenolic compounds which triggers the generation of brown or dark pigments. Browning incidence (BI) directly influences the fruit's acceptability and marketability. Therefore, different exposure times (5mins, 10mins, $15 \mathrm{mins}$ and $20 \mathrm{mins}$ ) and types of LED lights (white, red and blue) were applied on fresh-cut pineapple stored at $5^{\circ} \mathrm{C}$ storage for twelve days to reduce BI. A significant interaction between the two factors was recorded in lightness coefficient, chroma, total phenolic and ascorbic acid (AA) contents. Regardless of exposure times, all types of LED lights, mainly the blue light, succeeded in delaying BI in fresh-cut pineapple. In conclusion, blue light had a tendency to delay BI and maintain the other postharvest quality attributes of fresh-cut pineapple.
\end{abstract}

Keywords: Chiller, Josapine, minimally processed, postharvest, wavelength

\section{Introduction}

Pineapple (Ananas comosus L.) is the leading edible member of the family Bromeliaceae and widely grown in tropical and subtropical countries including Philippines, Thailand, Indonesia, Malaysia, Kenya, India, and China. In Malaysia, pineapple plantations are mainly concentrated in Johor due to its enriched peat soil which is suitable for the fruit. Based on Agrofood statistic (2015), the production of Malaysian pineapple increased from 2013 to 2015 due to the high demand by domestic and export markets. Even though the production of pineapple has been high, severe postharvest loss has occurred due to improper handling from farms to consumer plates. Recently, Hossain and Bepary (2015) reported that the quantity of pineapple spoiled is between $15-25 \%$ due to improper postharvest handling process in developing countries. In addition, pineapple is also categorized as non-climacteric fruit that is highly perishable and easy to deteriorate once harvested (Ko et al., 2006). Moreover, the respiration rate is higher than other fruits. To date, one of the alternatives to reduce loss is by converting pineapple into ready-to-eat product. However, fresh-cut pineapple also increases postharvest loss due to its very short shelf life and browning incidence. According to Marrero and Kader (2001), fresh-cut pineapple can only be stored for four days at $10^{\circ} \mathrm{C}, 12$ days at $5^{\circ} \mathrm{C}$ and two weeks at $0^{\circ} \mathrm{C}$. The temperature between $0^{\circ} \mathrm{C}$ and $5^{\circ} \mathrm{C}$ is not normally used for marketing of fresh-cut pineapple. In contrast, $10^{\circ} \mathrm{C}$ is the most widely used temperature commercially for fresh-cut pineapple.
Therefore, it is important to maintain the quality and prolong the shelf life of fresh-cut pineapple, so that the profit can be increased for this business.

Furthermore, fresh-cut pineapple is perishable fruit that easily deteriorates due to various factors such as physical, chemical and biological reactions. This results in changing of flavor and texture, decreased nutritional value as well as reduction of storage time. Fresh-cut pineapple changes the flesh colour from yellow to brown within 24 hours when stored at ambient temperature. This browning incidence has become the main problem in fresh-cut industry because it reduces acceptability by consumers. Many studies have been conducted to reduce browning incidence in fresh-cut pineapple by applying various chemical based antibrowning agents. However, some chemical treatments have negative effects on human health and also increase production cost. Hence, physical treatment such as using light emitting diodes (LED) may be the suitable alternative to replace the chemical-based treatments. Kim et al. (2013) claimed that LED could reduce browning incidence by decreasing melanin production through inhibition of the production of tyrosine. In addition, blue light maintained the quality and prolonged the shelf life of strawberry fruit, as reported by $\mathrm{Xu}$ et al. (2014). LED light is cheap, safe and durable, and there is a lack of information about its browning retarding effect in fresh-cut produce. Therefore, this study aimed at evaluating the effect of different exposure times of LED lights on browning 
incidence and postharvest quality of fresh-cut pineapple.

\section{Materials and Methods \\ Plant Materials and Experimental Location}

Josapine pineapples with maturity index 3 were purchased from Gong Pauh wholesale market, Terengganu. The experiment was conducted at the Postharvest Technology Laboratory located in the School of Food Science and Technology, Universiti Malaysia Terengganu. The experiment was carried out for 12 days starting from 20 December 2017 to 1 January 2017.

\section{Preparation of Sample and Experimental Design}

A total of 78 of Josapine pineapples were used in this experiment. All the pineapples were washed with 200 ppm of sodium hypochlorite to remove dirt and prevent the microorganism infection. All the equipment was sanitized with $70 \%$ ethanol and left to air-dry. Next, the pineapple peel, crown and fruitlets were removed and the pineapples cut into wedges, each measuring $2 \mathrm{~cm}$ thick and $3 \mathrm{~cm}$ wide. The experiment was laid out in a complete randomized design (CRD) with two factors viz; i) three LED lights in white, blue $(470 \mathrm{~nm})$ and red $(650 \mathrm{~nm})$ and four exposure times: (i) 5 minutes, (ii) 10 minutes, (iii) 15 minutes and (iv) 20 minutes on freshcut pineapple. The treatments applied included (i) white LED light (control) with 5 minutes exposure time, (ii) white LED light (control) with 10 minutes exposure time, (iii) white LED light (control) with 15 minutes exposure time, (iv) white LED light (control) with 20 minutes exposure time, (v) red LED light with 5 minutes exposure time, (vi) red LED light with 10 minutes exposure time, (vii) red LED light with 15 minutes exposure time, (viii) red LED light with 20 minutes exposure time, (ix) blue LED light with 5 minutes exposure time, $(\mathrm{x})$ blue LED light with 10 minutes exposure time, (xi) blue LED light with 15 minutes exposure time and (xii) blue LED light with 20 minutes exposure time with three replications. For each treatment, three pineapple wedges were used as experimental units. The duration of the experiment was 12 days and the parameters were evaluated at every three-day interval viz. $0,3,6,9$ and 12 days.

\section{Postharvest Parameters}

Parameters evaluated included weight loss, flesh colour, browning index (BI), firmness, titratable acidity, soluble solids and ascorbic acid concentrations. The BI of fresh cut-pineapple was evaluated according to the report of Ding et al. (2007). The BI was visually evaluated at three-day intervals for each cutting area according to the following scales: $0=$ no browning ( 0 $20 \%) ; 1=\operatorname{trace}(20-40 \%) ; 2=\operatorname{slight}(40-60 \%) ; 3=$ moderate $(60-80 \%) ; 4=$ severe $(80 \%)$ and $5=$ extremely severe (>100\%). Meanwhile, the flesh colour of fresh-cut pineapple was measured using Kinoca Minolta CR-400 (Minolta camera Ltd, Japan) according to CIELAB colour parameters. Fruit colour data were expressed in lightness $\left(\mathrm{L}^{*}\right)$, chromaticity value $a^{*}$ and chromaticity value $b^{*}$ (McGuire, 1992). $\mathrm{L}^{*}$ represents the lightness coefficient which ranges from 0 (black) to 100 (white) while $\mathrm{a}^{*}$ represents the position between red (+) and green (-) while $b^{*}$ is the scale between blue (-) and yellow (+). Chromaticity value $a^{*}$ and $b^{*}$ were further used to calculate chroma $\left[\mathrm{C}^{*}=(\mathrm{a} 2+\mathrm{b} 2) 1 / 2\right]$ and hue angle $\left(\mathrm{h}^{\circ}=\tan -1 \mathrm{~b} * \mathrm{a}^{*}\right)$ for colour interpretation. Chroma corresponded to the intensity or colour saturation, where low values represent dull colour while high values represent vivid colour. Hue angle represented red-purple $\left(0^{\circ}\right)$, yellow $\left(90^{\circ}\right)$, bluish green $\left(180^{\circ}\right)$ and blue $\left(270^{\circ}\right)$. The colour measurements were taken on the upper, middle and bottom part of pineapple wedges. For the percentage of fruit weight determination, the fruit samples were weighed during the sampling days and calculated using the formula PWL $(\%)=($ Initial weight-Final Weight $) /($ Initial weight $) \times 100$. The firmness of fresh-cut pineapple was determined using TX plus texture analyser (Stable Micro Systems, United Kingdom). The probe of $\mathrm{P} / 2$ stainless needle was used to penetrate the flesh of the pineapple wedges with a test speed of 1 $\mathrm{mm} / \mathrm{sec}$. The pre-test speed and the post-test speed were set as $5 \mathrm{~mm} / \mathrm{sec}$ and the target distance was adjusted to $10 \mathrm{~mm}$. The firmness readings were taken on the upper, middle and bottom part of pineapple wedges and the readings were expressed in Newton $(\mathrm{N})$. SSC was measured individually by means of a handheld refractometer (AOAC, 1990). The samples were sliced into smaller pieces and squeezed into juice by using muslin cloth and the readings were expressed as $\%$ Brix. Total phenolic content of fresh-cut pineapple was determined according to Wan Zaliha and Koh (2016). The total phenolic content was determined by using standard curve obtained and expressed as milligrams of gallic acid equivalents per 100 grams of fresh weight (mg GAE 100g-1 FW). Ascorbic acid concentration was determined by using indophenol titration method according to AOAC (2004). The concentration of ascorbic acid was determined by using the standard curve obtained and expressed as mg per $100 \mathrm{~g}$ fresh weight.

\section{Statistical Analysis}

The data were subjected to analysis of two-way variance (ANOVA) using GLM (General Linear Models) procedures with SAS 9.4 software package, SAS Institute Inc, Cary, NC, USA. Treatment means were further separated by Tukey for least significance at $\mathrm{P} \leq 0.05$ (SAS Institute Inc. 1999).

\section{Results and Discussion}

Physical damage occurred during the processes of peeling and cutting causes an increase in respiration 
rate, biochemical changes and microbial spoilage, degradation of colour, texture and flavour of the produce (Gonzalez-Aguilar et al., 2005). These cutting and peeling processes are the main factors that accelerate browning incidence which lead to loss of marketable quality and this remains a major challenge for fresh-cut industry. Fruit browning occurs as the consequence of the destruction of fruit cellular compartmentation which allows the phenolic substrates to be accessible to polyphenoloxidase (PPOs) which catalyse the phenolic oxidation (Cheng and Carlos, 1995). Irina and Mohamed (2013) stated that PPO catalyse two reactions which are hydroxylation of monophenols to diphenols to make discolourations and then, oxidation of diphenols to quinones and form coloured products like brown pigments. In the present study, all treated fruit had increased browning incidence along the storage period (Table 1). However, the interaction between exposure times and LED lights had no apparent effect on the browning index of fresh cut pineapple. However, regardless of exposure time, types of LED lights had significantly affected the browning incidence for fresh cut pineapple. Blue light had more potential to delay browning incidence (score 2). As illustrated in Table 1, the fruit maintained pure yellow colour of flesh with only a very mild browning throughout the storage periods. However, red light had the highest browning score with 3 . In contrast, LED light exposure at various periods had no effect on browning index of fresh-cut pineapple but it showed increased trend among treatments. This is congruent with Rocha and Moris (2001), in that 'Jonagored' apple increased PPO activity with increased storage time and when stored at low temperature. Browning incidence is closely related to phenolic compound and ascorbic acid.

Table 1: Effects of different exposure times of LED lights on browning index of fresh-cut

\begin{tabular}{|c|c|c|c|c|c|}
\hline & Day 0 & Day 3 & Day 6 & Day 9 & Day 12 \\
\hline $\begin{array}{c}\text { White light wi } \\
5 \text { minute } \\
\text { exposure }\end{array}$ & & & & & \\
\hline $\begin{array}{c}\text { White light wi } \\
10 \text { minutes } \\
\text { exposure }\end{array}$ & & & & & \\
\hline $\begin{array}{c}\text { White light wi } \\
15 \text { minutes } \\
\text { exposure }\end{array}$ & & & & & \\
\hline $\begin{array}{c}\text { White light wi } \\
20 \text { minutes } \\
\text { exposure }\end{array}$ & & & & & \\
\hline $\begin{array}{l}\text { Red light with } \\
\text { minutes expost }\end{array}$ & & & & & \\
\hline $\begin{array}{l}\text { Red light with } \\
\text { minutes exposu }\end{array}$ & & & & & \\
\hline $\begin{array}{l}\text { Red light with } \\
\text { minutes exposu }\end{array}$ & & & & & \\
\hline $\begin{array}{l}\text { Red light with } \\
\text { minutes exposu }\end{array}$ & & & & & \\
\hline $\begin{array}{l}\text { Blue light with } \\
\text { minutes exposu }\end{array}$ & & & & & \\
\hline $\begin{array}{l}\text { Blue light with } \\
\text { minutes exposu }\end{array}$ & & & & & \\
\hline $\begin{array}{l}\text { Blue light with } \\
\text { minutes exposu }\end{array}$ & & & & & \\
\hline $\begin{array}{l}\text { Blue light with } \\
\text { minutes exposu }\end{array}$ & & & & & \\
\hline White light & & & & & \\
\hline Red light & & & & & \\
\hline Blue light & & & & & \\
\hline
\end{tabular}


*Some photos were not available on day 12 of analysis because the shelf life of the pineapple in the treatments had to be terminated earlier due to unacceptable condition. The browning index score indicates the following: $0=$ no browning $(0-20 \%) ; 1=\operatorname{trace}(20-40 \%) ; 2=\operatorname{slight}(40-60 \%) ; 3=$ moderate $(60-80 \%$

Degrees of browning incidence can be determined by measurement of lightness coefficient $\left(\mathrm{L}^{*}\right)$ and chromaticity b* (Gonzalez-Aguilar et al., 2004). L* value represents brightness and $b^{*}$ value represents loss of yellow colour or browning incidence. In general, high values of lightness coefficient $\left(\mathrm{L}^{*}\right)$ and chromaticity $\mathrm{b}^{*}$ reflect lower extent of browning incidence, as stated by Wan Zaliha and Koh (2017), for minimally processed carambola. Similar results were achieved, where blue light with 20 minutes exposure had the highest value of $\mathrm{L}^{*}$, which was 74.53, whereas red light with 5 minutes exposure had the lowest value, which was 67.72 , among treatments at the end of storage day (Figure 1).

This means that red light with 5 minutes exposure had more severe browning incidence occurred on fresh cut pineapple compared with other treatments. Therefore, it can be suggested that the longer the exposure times, the lower the browning score obtained and vice versa. Meanwhile, blue light had more potential in delaying browning incidence of fresh-cut pineapple compared with red and white lights. Chromaticity $b^{*}$ of fresh-cut pineapple was maintained due to no significant effect among treatments. However, the results showed that blue light had higher value of chromaticity $b^{*}$ ranging between 19 and 23 compared with red and white lights; hence, this coincided with previous statements (Figures 2 and 3). The interaction between exposure times and types of LED lights had no apparent effect on the chromaticity $\mathrm{a}^{*}$, but all the pineapple samples had a relatively low value of chromaticity a* (Figures 4 and 5). This is because pineapple is non-climacteric fruit that undergoes little or desirable change in composition such as chlorophyll loss and change in phenolic compound after being harvested (Wills et al., 2004).

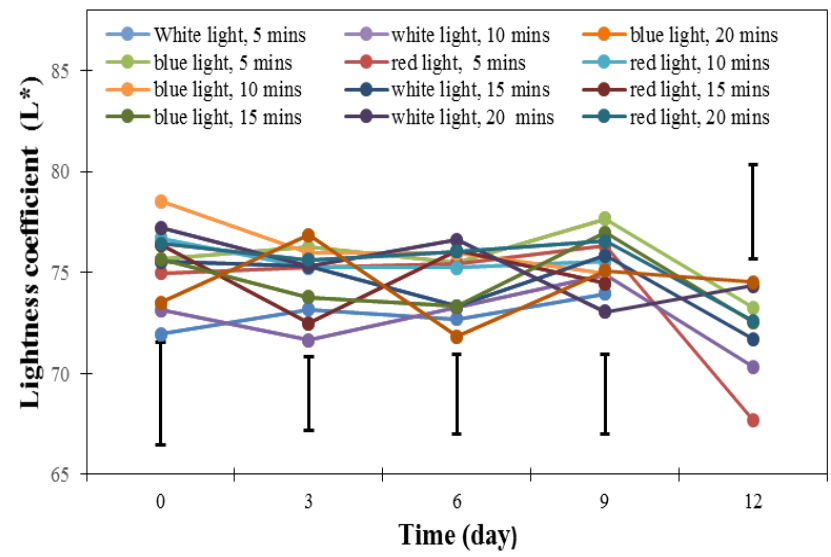

Figure 1: Effects of different exposure times of LED lights on lightness coefficient of fresh- cut pineapple. Vertical bars represent HSD at 5\% level. (HSD values on Day 0=5.13, Day 3=3.63, Day 6=3.94, Day 9=3.96 and Day $12=4.68$ )

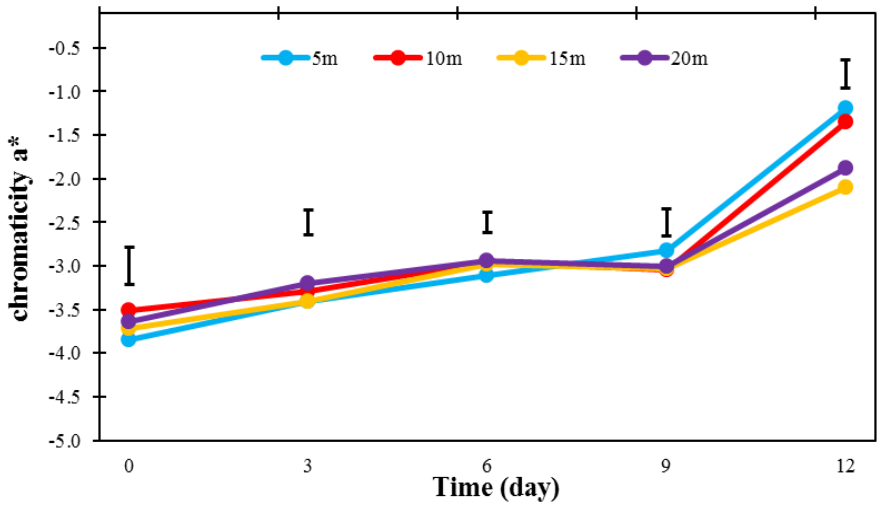

Figure 2: Effects of different exposure times on chromaticity a* of fresh-cut pineapple. Vertical bars represent HSD at $5 \%$ level. (HSD values on Day $0=0.42$, Day $3=0.29$, Day $6=0.23$, Day $9=0.31$ and Day $12=0.32$ ) 


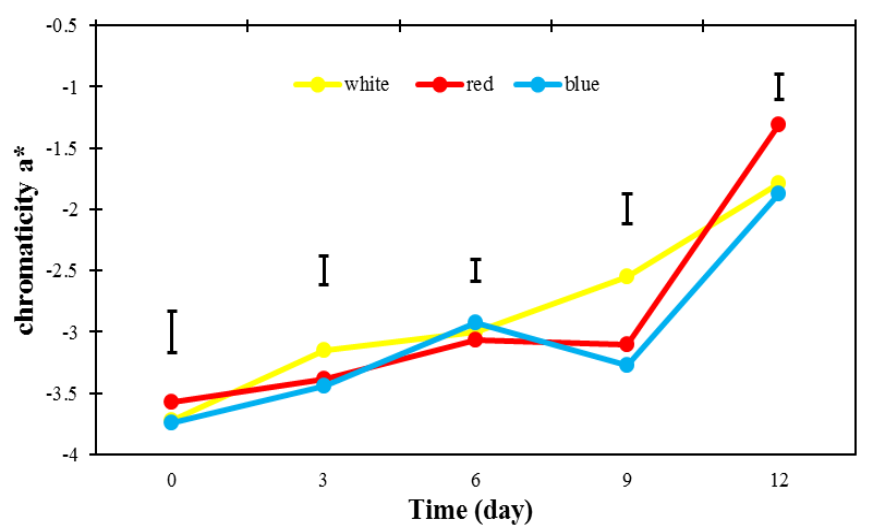

Figure 3: Effects of different LED lights on chromaticity a* of fresh-cut pineapple. Vertical bars represent HSD at $5 \%$ level. (HSD values on Day $0=0.33$, Day $3=0.23$, Day $6=0.18$, Day $9=0.24$ and Day $12=0.21$ )

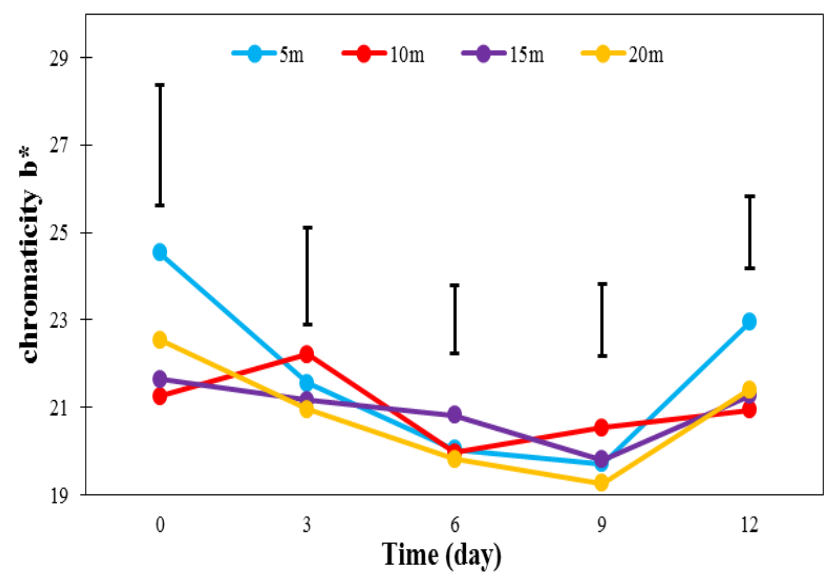

Figure 4: Effects of different exposure times on chromaticity $b^{*}$ of fresh-cut pineapple. Vertical bars represent HSD at $5 \%$ level. (HSD values on Day $0=2.74$, Day $3=2.24$, Day $6=1.55$, Day $9=1.64$ and Day $12=1.67$ )

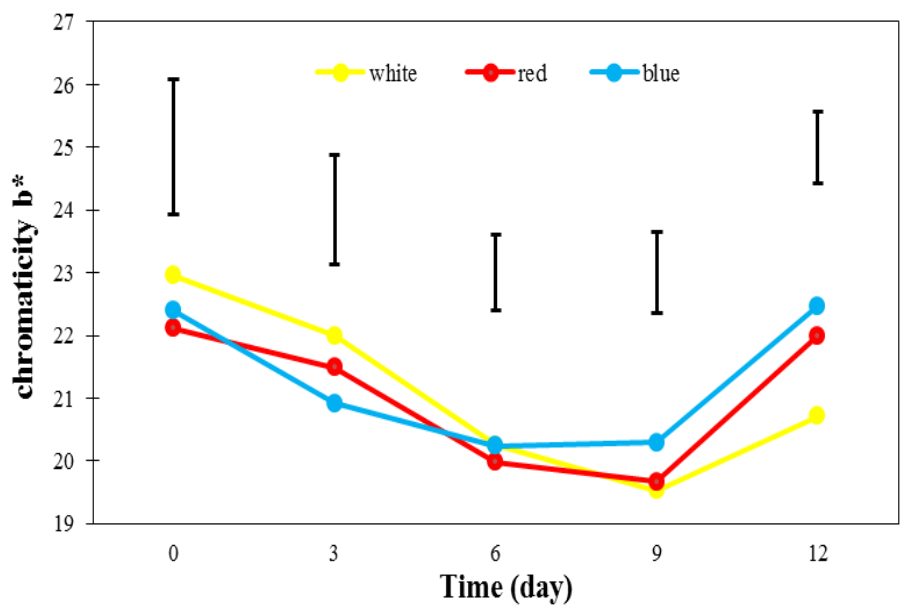

Figure 5: Effects of different LED lights on chromaticity b* of fresh-cut pineapple. Vertical bars represent HSD at $5 \%$ level. (HSD values on Day $0=2.15$, Day $3=1.75$, Day $6=1.22$, Day $9=1.29$ and Day $12=1.13$ )

Ascorbic acid is widely used as anti-browning agent in fruits and vegetables (Rupasinghe et al., 2005) which is able to reduce or delay the browning incidence (elShimi, 1993; Hussein et al,, 2015; Techavuthiporn and Boonyaritthonghai, 2016). Ascorbic acid is a prosthetic group of the polyphenol oxidase, thus it can reduce quinones back to phenols before forming dark pigments (Limbo and Piergiovanni, 2006; Hussein et al., 2015). In the present study, all treatments resulted in increased ascorbic acid concentration ranging between 18 and $63 \mathrm{mg} / 100 \mathrm{~g}$ FW (Figure 6). This shows that LED lights has potential in reducing browning incidence on fresh- 
cut pineapple. This may be attributed to the presence of single-spectral red or blue LEDs that increase accumulation of plant metabolites in both primary and secondary in terms of soluble sugars, vitamin C and polyphenol, compared with white light (Li et al., 2012). On the other hand, LED irradiation is effective for enriching vitamin $\mathrm{C}$ of cabbage stored at low temperature with different wavelengths (Lee et al., 2014). In the present study, a significant interaction was recorded between exposure times and types of LED lights (Figure 6 ). On day 6 , the highest value was observed in blue light with 5 minutes exposure $(62.17 \mathrm{mg} / 100 \mathrm{~g} \mathrm{FW})$ whereas white light with 20 minutes exposure showed the lowest concentration of ascorbic acid with the value of $41.303 \mathrm{mg} / 100 \mathrm{~g} \mathrm{FW}$. This is in agreement with Lee et al. (2014), where stored cabbage exposed under blue light had the highest amount of vitamin $\mathrm{C}$, followed by white, green, red and the control. On top of that, Zhang et al. (2015) also claimed that blue light treatment effectively increased the ascorbic acid content in the juice sacs of three different citrus varieties compared with red light. Possibly, mono-dehydroascorbate (MDAR) and dehydroascorbate, (DHAR) are the enzymes responsible for ascorbic acid regeneration in plants while ascorbic acid can be elevated in plants by increasing the gene expression of MDAR and DHAR. This gene expression was up-regulated by blue LED light (Nishikawa et al., 2003). Therefore, blue light has potential to delay browning incidence due to high ascorbic acid concentration as indicated by the results taken from browning incidence and colour parameters. This might be ascribed to ascorbic acid having the ability to control activity of PPO by reducing the formed $\mathrm{O}$-quinones back to their phenolic substrate oxidizing itself into dehydroascorbic acid (Oms-Oliu et al., 2010). In other words, quinones can accumulate and undergo browning once the ascorbic acid has been oxidised, hence treatments may reduce the browning by maintaining higher vitamin C (Zahra et al., 2013).

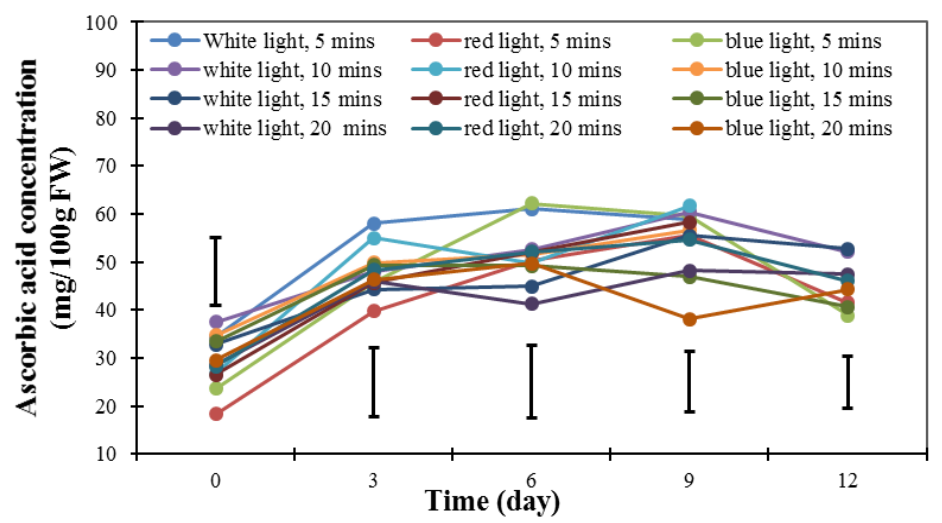

Figure 6: Effects of different exposure times of LED lights on ascorbic acid concentration of fresh-cut pineapple. Vertical bars represent HSD at 5\% level. (HSD values on Day $0=14.09$, Day 3=14.28, Day 6= 15.10, Day $9=12.54$ and Day $12=10.8$ )

Weight loss is closely related to moisture loss as water is the main component in fresh produce. Wills et al. (2004) demonstrated that water loss is equal to loss of weight and thus constitutes a direct loss in marketing. Generally, the percentage of weight loss of fresh-cut pineapple significantly increased for all types of LED lights throughout the experimental period (Figure 7). Ozturk et al. (2015) claimed that the moisture loss is expected to occur during the postharvest storage of fresh fruits and vegetables. As illustrated in Figure 8, blue light had greater tendency to cause loss of weight while white light had the least percentage to cause weight loss throughout the experimental period. This coincides with Joaquin et al. (2016), for broccoli. Hasan et al. (2017) found that blue LED lights facilitate moisture loss by transpiration during postharvest storage of the crop produce whereas red LED lights aid in moisture retention in tissues of fruit and vegetables. Generally, the breakpoint implemented for quality maintenance of fruits and vegetables occurs when the moisture content drops by $5 \%$ (Lee, 2006). However, as the results showed, all treated fresh-cut pineapple had a moisture content drop of less than $5 \%$ during the experimental period; thus, its quality was maintained. Nevertheless, exposure time had no apparent effect on the percentage of weight loss of fresh-cut pineapple along the storage period regardless of LED lights. However, further investigation is required to explain the exposure times in maintaining the flesh weight of pineapple. 


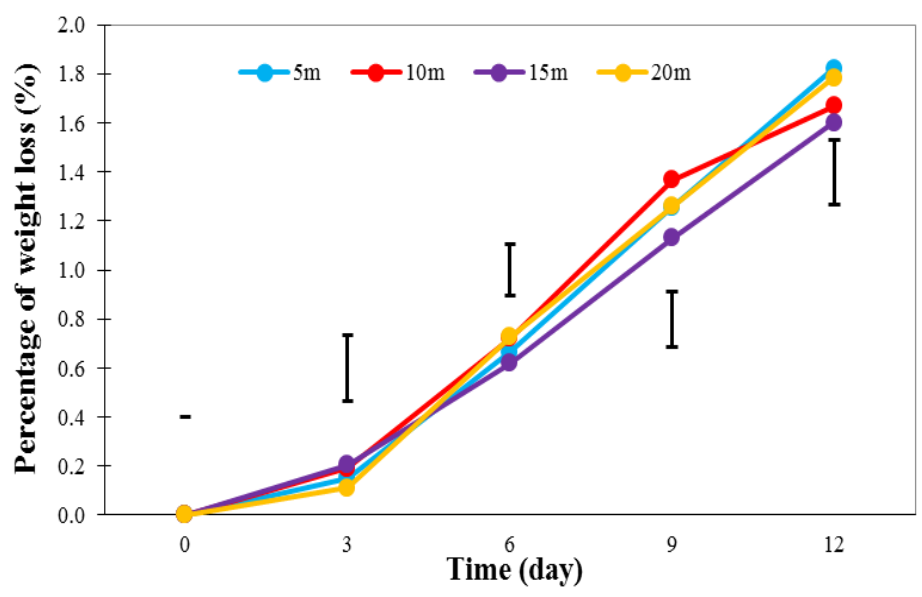

Figure 7: Effects of different exposure times on percentage weight loss of fresh-cut pineapple. Vertical bars represent HSD at $5 \%$ level. (HSD values on Day $0=0$, Day $3=0.27$, Day $6=0.21$, Day 9=0.22 and Day $12=0.26$ )

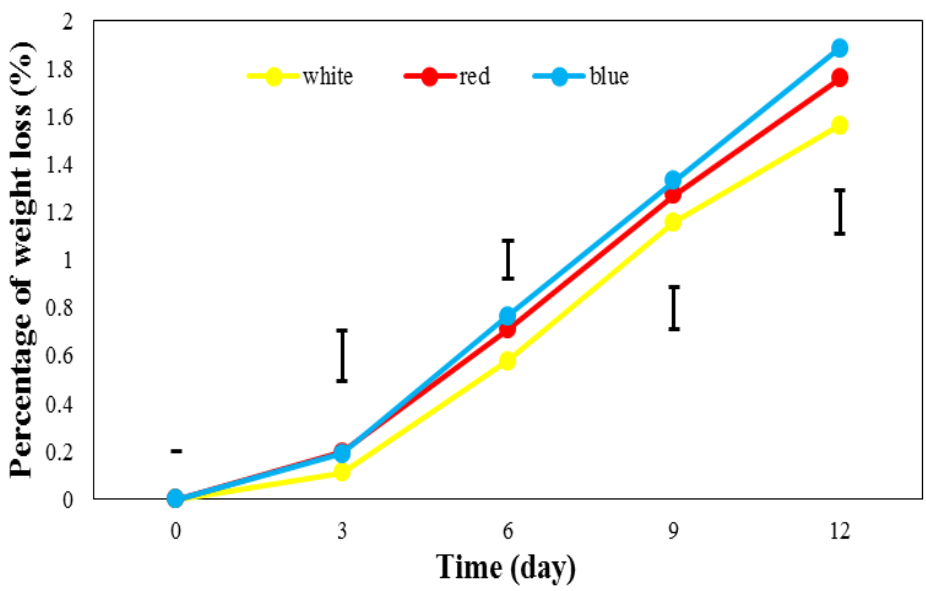

Figure 8: Effects of different LED lights on percentage weight loss of fresh-cut pineapple. Vertical bars represent HSD at $5 \%$ level. (HSD values on Day $0=0$, Day $3=0.21$, Day $6=0.16$, Day $9=0.18$ and Day $12=0.18)$

Texture is a critical quality attribute influencing consumer acceptability of fresh fruit and vegetables. Wills et al. (2004) claimed that polymeric carbohydrates break down especially pectin substances and hemicelluloses, weaken cell wall and the cohesive force binding cell together. Similarly, the softening of fresh fruit and vegetables might be attributed to the conversion of starch and sugar and the breakdown of pectin substances, as stated by Thompson (1996). In other words, the rate of degradation of pectin substances is directly correlated with the rate of softening of fruits. Fresh-cut pineapple is highly perishable and rapid loss of firmness when exposed in unsuitable condition contributes greatly to its short postharvest life and to it being susceptible to fungal contamination as well as lowers its acceptability and marketability. Generally, the firmness of pineapple flesh is decreased with the increase in storage time among treatments, which is in agreement with Gonzalez-Aguilar et al. (2004). This is because fresh-cut pineapple is exposed to the environment either at room or chilling temperature that induces water loss due to dissolution of pectin substances through the activation of pectin methyl-esterase and polygalacturonase enzyme which hydrolyze the cell wall structure prior to maturation stage (Adams, 1991). However, the firmness of fresh-cut pineapple of all treatments remained unchanged over time. This result coincided with the observation of the appearance of the wedges, which kept their shape and size throughout storage periods at $5^{\circ} \mathrm{C}$ (Table 1). Similarly, Gil et al. (2006) and Wu et al. (2012) found that the firmness of minimally processed pineapple did not change along the experimental period at low storage temperature. This is because pineapple is known as non-climacteric fruit which shows comparatively low profile and a gradual decline in respiration process and ethylene production (Wills et al., 2004). The results therefore showed that exposure time and types of LED lights had no significant impact respectively on tissue firmness of fresh cut pineapple during experimental period at store temperature of $5^{\circ} \mathrm{C}$ (Figures 9 and 10). 
In general, the high SSC during ripening might be due to the hydrolysis of starch into sugar by phosphorylase enzyme in the fruit. Hence, the decreasing trend in titratable acidity could be due to the increase in soluble solid concentration as the organic acid declines as it is respired or converted into sugar (Wills et al., 2001). The SSC of fresh-cut pineapple exposed with different exposure times had no pronounced effect as shown in Figures 11 and 12. The trend was maintained constantly for different exposure time, ranging between $9 \%$ and $12 \%$. This coincides with Mantilla et al. (2013) who stated that pineapple is a non-climacteric fruit that will not experience any climacteric peak during its storage life, hence the sugar content does not vary extremely. However, exposure to different LED lights significantly affected the soluble solid concentration. The increased value in sugar might be attributed to the ripening process. Meanwhile, the decreased in sugar might be due to the oxidation of substrate that occurred during respiration process in high oxygen content. On day 9, blue light had higher levels of soluble solid concentration compared with that in the control (white light) and red light during storage days. This coincides with Hasan et al. (2017) where blue light had pronounced effect on inducing the soluble sugar in fruits compared with that in the control (white light).
Meanwhile, there was no apparent effect on titratable acidity in fresh-cut pineapple throughout the experimental period (Figures 13 and 14). However, it showed fluctuation with decreasing trend in different exposure time and types of light respectively. This is similar to the report of Ding et al. (2007) and Wan Zaliha and Koh (2017). However, this may be due to the use of different fruit, which may be giving an impression that the level of titratable acidity differs in the each fruit and the method is destructive. Generally, shelf life of freshcut pineapple can be prolonged to at least 12 days when stored at $5^{\circ} \mathrm{C}$. This is not true in the present study, where some treated fruit could be stored to 9 days only, which may be due to failure of food processing since the pineapples were not immediately applied the treatment after cutting, rendering microbial growth. This explains the reason for the mold growth after day 9 in fresh-cut pineapple receiving irregular treatment.

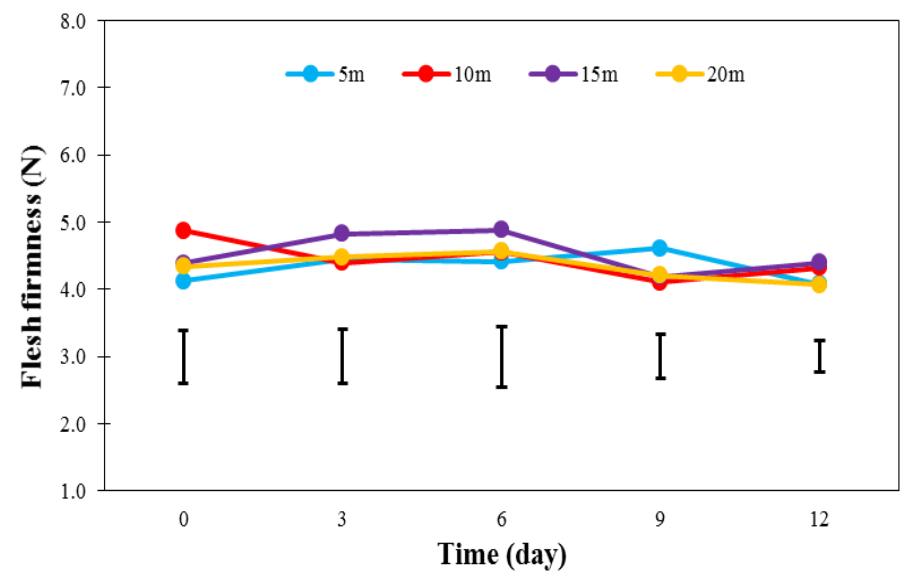

Figure 9: Effects of different exposure times on flesh firmness of fresh-cut pineapple. Vertical bars represent HSD at $5 \%$ level. (HSD values on Day $0=0.78$, Day $3=0.80$, Day $6=0.90$, Day $9=0.65$ and Day $12=0.48$ )

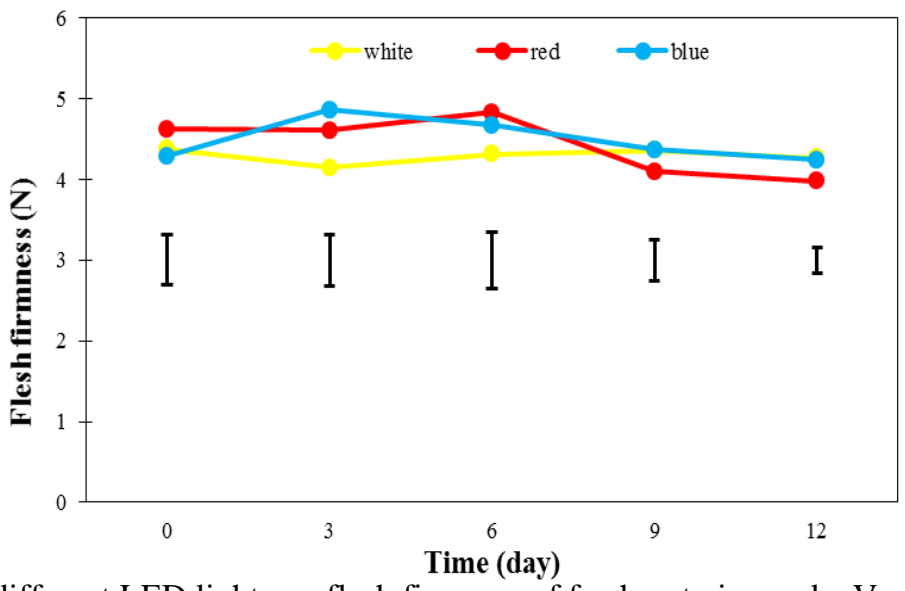

Figure 10: Effects of different LED lights on flesh firmness of fresh-cut pineapple. Vertical bars represent HSD at $5 \%$ level. (HSD values on Day $0=0.61$, Day $3=0.63$, Day $6=0.71$, Day $9=0.51$ and Day $12=0.32$ ) 


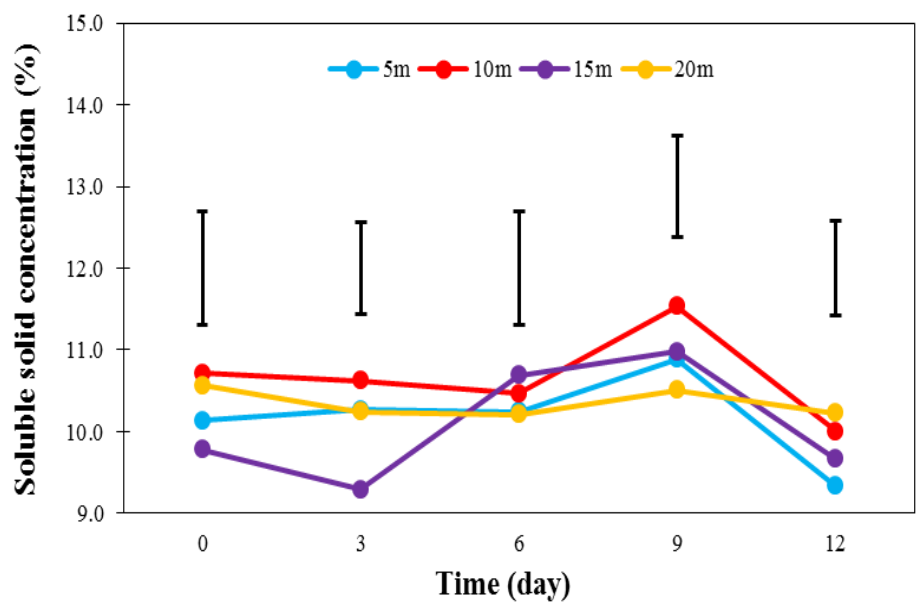

Figure 11: Effects of different exposure times on soluble solid concentration of fresh-cut pineapple. Vertical bars represent HSD at 5\% level. (HSD values on Day 0=1.38, Day 3=1.13, Day 6=1.39, Day 9=1.24 and Day $12=1.17$ )

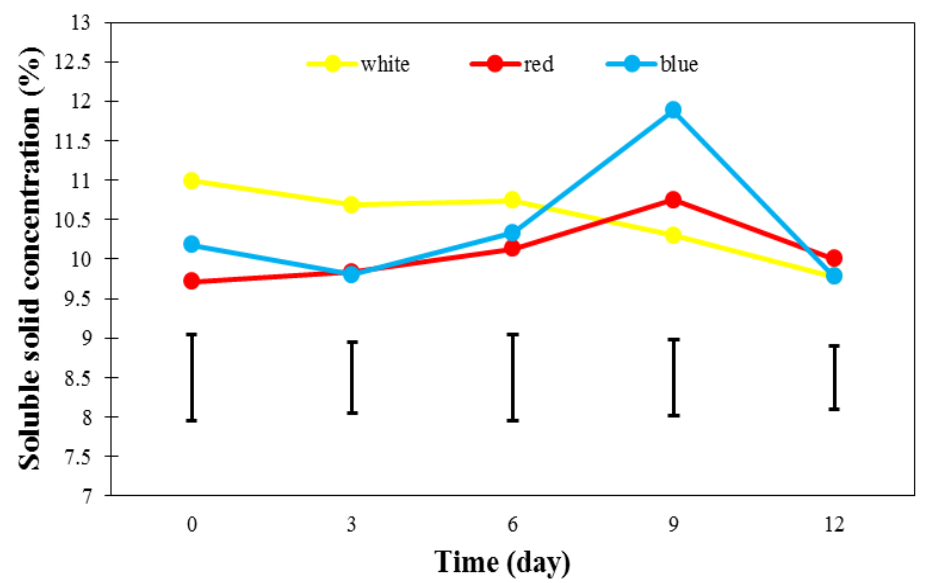

Figure 12: Effects of different LED lights on soluble solid concentration of fresh-cut pineapple. Vertical bars represent HSD at 5\% level. (HSD values on Day $0=1.08$, Day $3=0.89$, Day $6=1.09$, Day 9=0.97 and Day $12=0.79)$

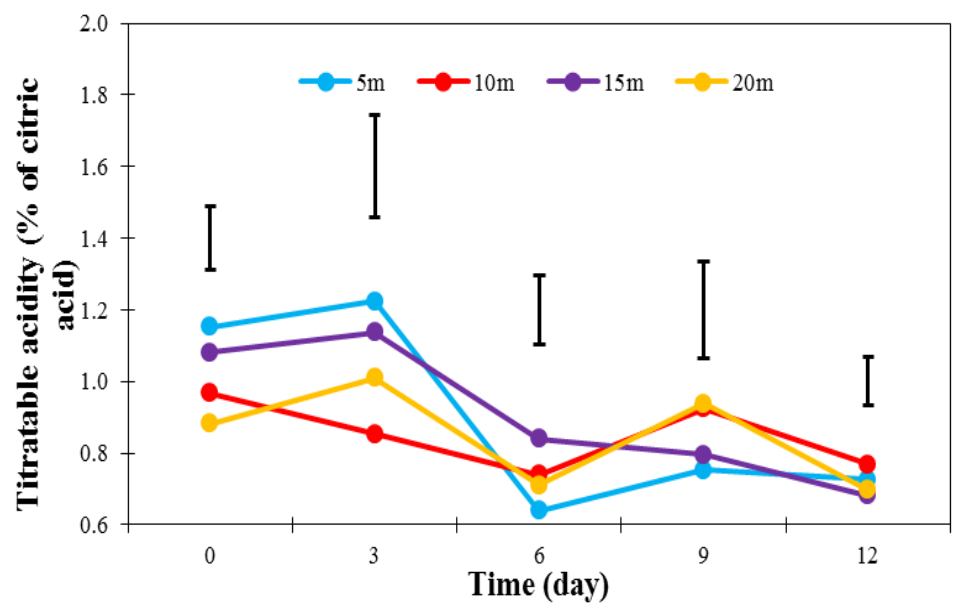

Figure 13: Effects of different exposure times on titratable acidity of fresh-cut pineapple. Vertical bars represent HSD at $5 \%$ level. (HSD values on Day 0 $=0.18$, Day $3=0.28$, Day $6=0.20$, Day $9=0.27$ and Day $12=0.14$ ) 


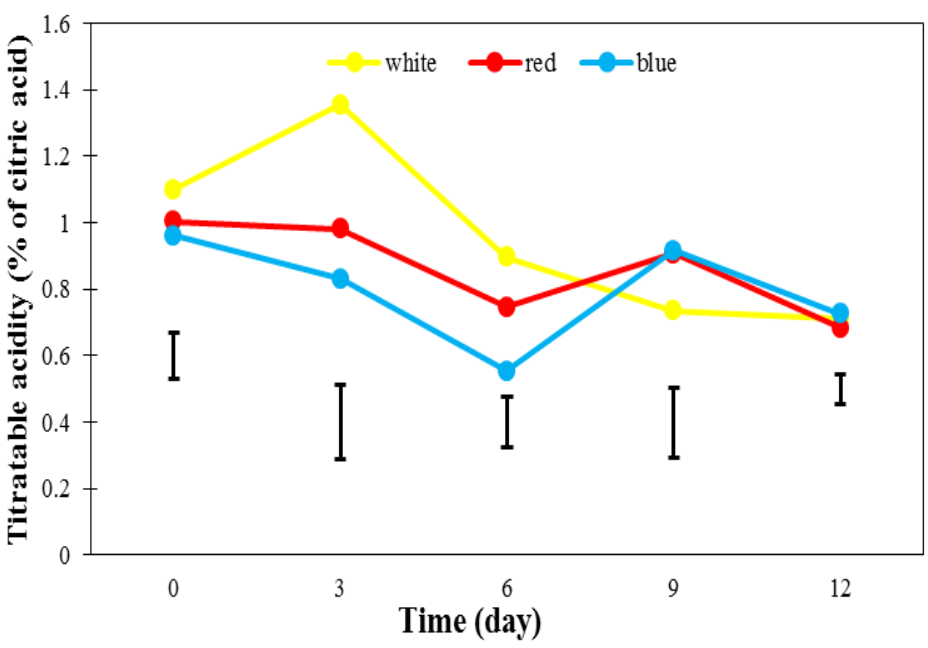

Figure 14: Effects of different LED lights on titratable acidity of fresh-cut pineapple. Vertical bars represent HSD at $5 \%$ level. (HSD values on Day $0=0.14$, Day $3=0.22$, Day $6=0.15$, Day $9=0.21$ and Day $12=0.09$ )

\section{Conclusion}

The different types of LED lights at varying exposure times were not effective in reducing browning incidence of fresh-cut pineapple stored at $5^{\circ} \mathrm{C}$. However, all LED light treatments with different exposure times were effective in maintaining the postharvest quality of freshcut pineapple. Although all treatments had no effect on all postharvest quality attributes of fresh-cut pineapple, blue LED light tended to show the ability to reduce browning incidence without significant reduction of other quality attributes. A future study on the sensory test of fresh-cut pineapple can be conducted to observe the acceptability by consumers. This is to make sure the fresh-cut pineapple is acceptable by consumers even though there is no change of appearance of fresh-cut pineapple. For further investigations, it is recommended to expose fresh-cut pineapple under fluorescent light as control and LED lights in whole storage time to effectively delay the occurrence of browning and prolong the shelf life of fresh-cut pineapple.

\section{Acknowledgements}

The authors wish to thank Universiti Malaysia Terengganu for the financial support and the staffs of Postharvest Technology Laboratory for their kind help.

\section{References}

Adams, J.B. (1991). Review: Enzyme inactivation during heat processing of food stuffs. International Journal of Food Science and Technology 26, 1-20.

Afam, I.O.J., Tonna, A.A., Godwin, R.A.M., Elohor, O.U., \& Oluwatoyin, O.O. (2017). Chapter 3: Processing and preservation of fresh-cut fruit and vegetable products. In: Ibrahim, K. (eds.) Postharvest Handling. In Tech. pp. 48-73.
Agrofood statistic, ( 2015). Ministry of Agriculture and Agro-based Industry, Malaysia.

AOAC. (2004). Official Methods of Analysis. 13 ${ }^{\text {th }}$ ed. Arlington: Association of Official Analytical Chemists. pp. 746.

Cheng, G.W., \& Carlos, H.C. (1995). Browning potential, phenolic composition, and polyphenoloxidase activity of buffer extracts of peach and nectarine skin tissue. Journal America Society Horticulture Science, 120, 835-838.

Ding, P., Siti Hajar, A. \& Hasanah, M.G. (2007). Changes in selected quality characteristics of minimally processes carambola (Averrhoa carambola L.) when treated with ascorbic acid. Journal of Science of Food and Agriculture, 87, 702709.

El-Shimi, N. M. (1993). Control of enzymatic browning in apple slices by using ascorbic acid under different conditions. Plant Foods Human Nutrition, 43: 71-76.

Gil, M.I., Aguayo, E., \& Kader, A.A. (2006). Quality changes and nutrient retention in fresh-cut versus whole fruits during storage. Journal Agriculture Food Chemistry, 54,4284-4296.

Gonzalez-Aguilar, G.A., Ruiz-Cruz, S., CruzValenzuela, R., Rodriguez-Felix, A., \& Wang, C.Y. (2004). Physiological and quality changes of freshcut pineapple treated with antibrowning agents. Journal of Swiss Society of Food Science and Technology. 37, 369-376.

Gonzalez-Aguilar, G.A., Ruiz-Cruz, S., Soto-Valdez, H., Vazqueez-Ortiz, F., Pacheco-Aguilar, R. \& Wang, C.Y. (2005). Biochemical changes of fresh-cut 
pineapple slices treated with antibrowning agents. International Journal of Food Science and Technology, 40, 377-383.

Hasan, M.M., Bashir, T., Ghosh, R., Lee, S.K, \& Bae, H. (2017). An overview of LEDs' effects on the production of bioactive compounds and crop quality. Molecules, 22. Pp. 1420.

Hossain, M. \& Bepary, R. H. (2015). Postharvest handling of pineapples: a key role to minimize the postharvest loss. International Journal of Recent Scientific Research. 6, 6069-6075.

Hossain, M.F., Akhtar, S., \& Anwar, M. (2015). Nutritional value and medicinal benefits of pineapple. International Journal of Nutrition and Food Sciences. 4,84-88.

Hu, H.G., Li, X.P., Chen, D., \& Chen, W.X. (2011). Effects of wax treatment on quality and postharvest physiology of pineapple fruit in cold storage. African Journal of Biotechnology 10, 75927603.

Hussein, M. A., Ahmed, M, El-Gizawy, Rawia, E. I., ElBassiouny, \& Mahmoud, A.S. 2015. Browning inhibition mechanisms by cysteine, ascorbic acid and citric acid, and identifying PPO-catechol-cysteine reaction products. Journal Food Science Technology, 52, 3651-3659.

Irina, I., \& Mohamed, G. (2013). Prevention of enzymatic browning in fruit and vegetables. European Scientific Journal, 9, 310-341.

Joaquin, H.H., Luciano, G., Luis, M.R., Alicia, R.C., \& Gustavo, A.M. (2016). Continuous white-blue LED light exposition delays postharvest senescence of broccoli. Journal of Food Science and Technology, 65, 495-502.

Kim, K.M., Kook, H.S., Jang Y.J., Lee, W.H., KamalaKannan, S., Chae, J.C., \& Lee, K.J. (2013). The effects of blue light emitting diodes on antioxidant properties and resistance to Botrytis cinerea in Tomato. Journal Plant Pathology and Microbiology, 4(9), 1-5.

Ko, H.L., Campbell, P.R., Jobin-Décor, M.P., Eccleston, K.L., Graham, M.W., Smith,M.K. (2006). The Introduction of Transgenes to Control Blackheart in Pineapple (Ananas comosus L.) cv. Smooth Cayenne by Microprojectile Bombardment. Euphytica., 150, 387-395.

Kulkarni, S. \& Karadbhajne, S. (2015). Influence of UV light exposure on shelf life extension of fresh cut fruits. International Journal of Advanced Research, 3, 1296-1306.
Lee, M.W. (2006). A study on the evaluation of freshness of refrigerated foods. MD thesis, Seoul National University, Seoul, Korea.

Lee, Y.J., Ha, J.Y., Oh, J.E., \& Cho, M.S. (2014). The effect of LED irradiation on the quality of cabbage stored at a low temperature. Food Science Biotechnology, 23, 1087-1093.

Li, H.M., Tang, C.M., Xu, Z.G., Liu, X.Y., \& Han, X.L. (2012). Effects of different light sources on the growth of non-heading Chinese cabbage (Brassica campestris L.). Journal Agricultural Science, 4, 262270.

Limbo, S., \& Piergiovanni, L. (2006). Shelf life of minimally processed potatoes part I. Effects of high oxygen partial pressures in combination with ascorbic and citric acids on enzymatic browning. Postharvest Biology and Technology, 39, 254-264.

Mantilla, N., Castell-Perez, M.E., Gomes, C. \& Moreira, M.G. (2013). Multilayered antimicrobial edible coating and its effect on quality and shelf-life of fresh-cut pineapple (Ananas comosus). Food Science and Technology 51, 37-43.

Marrero, A., \& Kader, A.A., (2001). Factors affecting the post-cutting life and quality of minimally processed pineapple. Acta Horticulturae. 553, 705- 706.

McGuire, R.G. (1992). Reporting of Objective Colour Measurement. Horticulture Science, 27, 1254-1255.

Nishikawa, F., Kato, M., Hyodo, H., Ikoma, Y., Sugiura, M., \& Yano, M. (2003). Ascorbate metabolism in harvested broccoli, Journal Experiment Botanical 54, 2439-2448.

Oms-Oliu G., Rojas-Graü M.A., González L.A., Varela P., Soliva-Fortuny R., Hernando M.I.H., Munuera I.P., Fiszman S., \& Martín-Belloso, O. (2010). Recent approaches using chemical treatments to preserve quality of fresh-cut fruit: A review. Postharvest Biology and Technology, 57, 139-148.

Ozturk, B., Celik, S. M., Karakaya, M., Islam, A., \& Yarilgac, T. (2015). Storagetemperature affects phenolic content, antioxidant activity and fruit quality parameters of cherry laurel (Prunus laurocerasus L.). Journal of Food Processing and Preservation, 41, 110.

Rocha, A.M.C.N., \& Morais, A.M.M.B. (2001). Polyphenoloxidase activity and total phenolic content as related to browning of minimally processed 'Jonagored' apple. Journal of the Science of Food and Agriculture, 82,120 -126. 
Rupasinghe, H.P.V., Murr, D.P., DeEll, J.R., \& Odumeru, J. (2005). Influence of Imethylcyclopropene and NatureSeal on the quality of fresh cut "Empire" and "Crispin" apples. Journal Food Quality, 28, 289-307.

SAS Institute Inc, (1999), SAS Online Document. Version 8. Cary. North Carolina, USA.

Thompson, A.K. (1996). Postharvest treatments, in Postharvest Technology of Fruit and Vegetables, In: Thompson, A.K. (eds.) Blackwell Publishing. Oxford, pp. 95- 124.

Wan Zaliha W.S. \& Koh, S.Y. (2017). Effects of nitrogen gas fumigation on postharvest quality of minimally processed starfruit (Averrhoa carambola L.) stored at low temperature. Journal of Malaysian Applied Biology, 46,189-198.

Wills, R., McGlasson, B., Graham, D., \& Joyce, D. (2004). Physiology and biochemistry. In: Postharvest. Washington: UNSW Press. p. 33-59.

Wu, Z.S., Zhang, M., \& Wang, S.J. (2012). Effects of high pressure argon and nitrogen treatments on respiration, browning and antioxidant potential of minimally processed pineapple during shelf life. Journal Science Food Agriculture, 92, 2250-2259.

Xu, F., Shi, L.Y., Chen, W., Cao, S.F, Su, X.G., \& Yang, Z.F. (2014). Effect of blue light treatment on fruit quality, antioxidant enzymes and radical-scavenging activity in strawberry fruit. Scientia Horticulturae $175,181-186$.

Zahra, J., Mahmood, G., \& Somaye, Z. (2013). A comparison of heat treatment and ascorbic acid on controlling enzymatic browning of fresh cuts apple fruit. International Journal of Agriculture and Crop Sciences, 5, 186-193.

Zhang, L.C., Ma, G., Yamawaki, K., Matsumoto, H., Yoshioka, T., Ohta, S., \& Kato, M. (2015). Regulation of ascorbic acid metabolism by blue LED light irradiation in citrus juice sacs. Plant science 233, 134-14. 